\title{
Lived Experiences of Softball Athletes in a State University: A Phenomenological Study
}

\author{
Kathy N. Garcia \\ kathy.garcia@lnu.edu.ph \\ College of Education, Leyte Normal University, Tacloban City,6500, Philippines
}

\begin{abstract}
Students enroll in school to earn and develop their innate skills and talents that would be beneficial for them in the future. In developing one's ability and talent, students should not only focus their attention on the academic aspects of learning but try as well to engage in varied activities that would enable them to grow holistically. Among the extracurricular activities that the school offers to the students are sports activities. The purpose of this study is to seek insights into the Lived Experiences of Softball Athletes in a certain state university in the Philippines. Purposive random sampling was done in the selection of participants. The achievement motivation theory provides a basis for this study. There is a psychological need for success in school, sports, occupation, and other competitive situations. This is a phenomenological study employing Colaizzi's method of data analysis through semi-structured interviews. The result of this study could provide insights into the lived experiences of softball athletes in a certain state university in the Philippines and their academic performance.
\end{abstract}

Keywords: Education, Lived Experiences, Qualitative single case study, Leyte, Philippines.

\section{Introduction}

Student-athletes on most college campuses today represent a particular population of students with unique challenges and needs different from their nonathletic peers. Student-athletes spend a couple of hours every week to practice and be physically prepared and even miss several classes especially if their sports are in season (Watt \& Moore, 2001). These athletes are also anticipated to perform well in their classes and earn grades sufficient enough for them to still become eligible in playing their chosen sports events. Such academic and athletic demands, particularly for freshman student-athletes, can be tough to balance.

Being part of the student-athlete culture has many advantages. A sports team helps to build the social network of the students. It serves as an avenue for meeting different people and gaining more friends. It helps the students as well as to grow in many aspects of/her personality such as time management, self-confidence, teamwork, and team support (Gloor 2012). Also, being an athlete gives the student training to gain good leadership because as athletes they are used to working with other people (Fuentes 2011).

Furthermore, being a student helps them to discover their innate capabilities and to share them with others. As Mia Hamm (2005) stated: throughout our lives, our self-esteem goes down when we feel like a failure, and feeling loved goes a long way. We all need to explore opportunities where we can be good at something and feel good at ourselves. Physical activities and self-confidence are terrific ways to build up your accomplishment and learn that after today's failure there's tomorrow's chance".

On the other hand, being a student-athlete can be very difficult during school days knowing that one has to do both sports and classwork (Chong, 2002). To overcome these difficulties, one must be able to do one or two extra hours every day after school and go immediately to sports training. To be a student-athlete, one must not be afraid to handle a multi-tasking responsibility and have less time for procrastination (Fuentes, 2011). In addition, to be a good student-athlete, a person must be able to spend a lot of time practicing and be prepared for all the distractions that can arise along the way, such as stress, accidents, and even sleep deprivation. A student-athlete, therefore, must have the patience to balance school and sports (TJM, 2012).

The primary purpose of this study is to seek insights into the challenges that student-athletes experience academically and in their personal development.

The researcher believes that this research study, provides information about their academic performance, while they are active at the same time in the field of softball as student-athletes. 


\section{Literature Review}

In a university setting, academic success is a challenge where student-athletes have to deal with demanding requirements (Padilla \& Baumer, 1994)). Time management may shape the academic and athletic success that varsity athletes achieve at university. Although varsity student-athletes may receive time management support from administrators of athletic programs (Gabbard \& Halischak, 1993; Klem \& Connell, 2004; Rhodes \& Nevill, 2004; Solomon, Battistich, Kim \& Watson, 1997; Stanton-Salazar, Vasquez, \& Mehan, 2000), this may not always be the case. It may be that some university varsity athletic programs provide a more significant academic supportive environment than others, including time management assistance. Being part of the varsity athletic program requires a massive amount of time and effort to address the need for practices, meetings, training, film sessions, and games.

The availability of academic engagement opportunities, particularly for first-year students, may play a key role in helping students time management and ultimately find success both in the classroom and on the playing field.

A study conducted by Jergovic (2001) found that athletes have higher grades than non-athletes, lower absentee levels, a significantly lower percentage of discipline referrals, a smaller percentage of dropouts, and higher graduation rates. Sitkowski (2008) conducted a study that purported positive benefits attributable to participation in high school sports and found that there were positive effects of sport participation on grades, self-concept, the base of control, and educational aspirations in addition to a negative impact on discipline problems. Stigman and Stephen (2000) investigated the relationship between high school sports academic achievement and they found out that the high participation group achieved higher academic success in three scales; class rank, overall GPA, and Math GPA. Females in the high participation group significantly outdone females in the low participation group.

Angelo (2003) found statistically significant differences with athletes earning higher cumulative GPAs and achieving higher test scores on the 10th grade of Florida Comprehensive Assessment Test in reading and mathematics than did non-athletes. As opposed to the findings stated above, different studies resulted negatively.

Tara (2005) in his review of studies found that there may be short-term improvements due to physical activity, specifically concerning concentration, but there is no well substantiated long-term improvement of academic achievement as a result of more vigorous physical exercise. Tremblay et al., (2000) found that in 6,923 grade 6 New Brunswick (age 12 years), physical activity showed a weak inverse association with academic achievement, but a positive association with self-esteem. Daley (2000) found that for 232 English boys and girls (13-16 years old) there is no relationship between self-reported physical activity and grade point average. Moreover, in children aged 13, 14, or 16 years, the duration of physical activity was negatively correlated with marks for English.

A study by Mock (2007) found that, overall, two-thirds of male athletes in all sports have a grade-point average that placed them in the bottom third of their class. Neither is the problem limited solely to men, as female athletes also have recorded much weaker academic records than non-athlete students. The seriousness in which student-athletes took their enthusiastic leisure participation may have crossed over into the severity placed into their academics. It takes a serious commitment (to both the athletic program and the academic institution) to remain a member of the softball program, and with the limited hours in a day, there is simply no time to waste if one is to fulfill academic and athletic duties. If student-athletes are truly serious about their softball participation, then they must also be serious with their academics, as failing marks would penalize student-athletes by disallowing them to participate in their desired leisure activity.

\section{Research Problem}

This study aimed to determine pertinent information regarding the lived experiences of softball athletes in a certain state university in the Philippines to describe and have a better understanding of the skills they encounter as student-athletes in the university. Specifically, it seeks to find an answer to the following questions:

1. How does being a student-athlete affects your academic performance and personal development?

2. What are the challenges that student-athletes encounter? 


\section{Theoretical Framework}

The Achievement Motivation Theory will serve as the basis of this study. According to this theory, the more achievements that they may gain from the sports activities, the higher they are motivated to continue their actions. The better the effect in engaging in different sports activities, the higher the tendency that the respondents would continue in doing those actions.

\section{Methodology}

This study is a qualitative phenomenological study utilizing Colaizzi's method of data analysis through semistructured interviews. As cited by Sosha (2012), Colaizzi's seven-step method are:

1) Each transcript is read and re-read to obtain a general sense of the whole content;

2) From the transcript, significant statements that pertain to the phenomenon under study were extracted and recorded on a separate sheet noting their pages and line numbers;

3) Meanings were formulated from these significant statements;

4) Formulated meanings were sorted into categories, clusters of themes, and subthemes;

5) Findings of the study were integrated into an exhaustive description of the phenomenon under study;

6) The fundamental structure of the phenomenon was described; and

7) Validation of the findings was sought from the research participants to compare the researchers' descriptive results with their experiences.

\subsection{Data Collection}

In the conduct of the study, the researcher sought the approval of the sports director and asked for a list of names of the Softball athletes. Upon providing the list of names of the softball athletes, participants were contacted, and a one on one interview was conducted using a semi-structured interview guide by the researcher. The interview was recorded through a cellular phone recorder. The following school and athlete selection criteria were used to purposively identify the participants of this study

\section{School Selection Criteria}

The identified school must be a university, training softball players to compete in the school, colleges, and university athletic association (SCUAA).

\section{Athlete Selection Criteria}

The athlete must be an active softball player competing in the school, colleges, and university athletic association (SCUAA). And must also be enrolled in the university the moment the study was conducted.

\subsection{Ethical Considerations}

The safety and confidentiality of the participant were carefully considered before, during, and after the study. Permission from the sports director was sought first before the conduct an interview of the softball athletes. Before the conduct of the interview, the participants signed the consent form first. Great care was taken to ensure that no physical or emotional harm will be experienced by the participant as a direct or indirect result of her participation in the study.

The researcher and students who conducted the interview were reminded to be careful in dealing with every person of the school. Interview transcripts were transcribed verbatim and it was sent back to the participant for accuracy and cross-checking. 


\subsection{Reflexivity Statement}

Only the direct statements given by the participants were subjected for analysis and interpretation to present a clearer picture of participants' experiences about their academic performance

\section{Results and Discussion}

Based on the different research procedures conducted about this study, the relevant finding was generated to present the experiences of Softball athletes in the university extensively.

\section{Theme 1: Time Management}

The participant reported on how she manages her time in both academics and sports training.

“.... Sanay na ako hit training. So na balance ko na it akon time. Pero kun mag exam, nag.eestudy ako syempre pero I do that after training na. I usually attend my training first."

“... . 9 years na ako nagmiminulay, amo sanay na ako. Pero tak mga iba nga teammates nga mga bag.o pala, danay nakukurian pa hira pag pagbalance hit ira oras."

Time management is never easy. Indeed, for many first-year students, the adjustment from a standardized time structured high school schedule (e.g., 9-3 pm) to a more non-structured university schedule (15 hours of class time per week with classes during different time slots - often day and nights) is challenging in and of itself. Although a study in an urban high school found no association between sports involvement and academic performance (Fisher, Juszczak, \& Friedman, 1996), the university setting may pose new challenges on young adults' time management in regards to their academic engagement. The stress of adjusting to a non-structured schedule is a difficult one without factoring in the impact of time commitments (e.g., practice and training) for varsity athletes. The availability of academic engagement opportunities, particularly for first-year students, may play a key role in helping students time management and ultimately find success both in the classroom and on the playing field.

\section{Theme 2: Privileges of Student-Athletes}

Student-athletes avail scholarships, limelight, travel to various places, full athletic apparel, and many more. But being a student-athlete is not as glamorous as many perceive it to be;

“... may scholarship kame. 100\% scholarship ha EVRAA/PALARO players, free dorm with food allowance monthly, and Iba pa nga incentives tikang hit university kun naka-champion ha Regional SCUUA or National SCUAA."

\section{Theme 3: Challenges Met by Student-Athletes in terms of Academic Performance.}

The level of obligation and dedication expected of any college student is high. Adding sports involvements in the equation requires an incredible level of concentration and time control. There's a complete difference in balancing the responsibilities of sports and academic work in college from that in high school. Though there's more freedom in college, there's also the big responsibility of taking care of the daily tasks that your parent or guardian may have done for you.

Student-athletes on most college campuses today represent a particular population of students with unique challenges and needs different from their nonathletic peers. Student-athletes on average spend over twenty hours per week in practice or play, sustain bodily injury and fatigue, and miss a fair number of classes when their sport is in season (Watt and Moore, 2001; Wolverton, 2008). These students are also expected to perform well in the classroom and earn grades strong enough to maintain their eligibility for playing college sports. 


\section{Theme 4: Factors that Affect the Academic Performance of Student-Athletes Coaches' Influence}

Coaches play one of the most significant roles in the educational experiences of student- athletes (Singer \& Armstrong, 2001) and can serve as the primary support person in the life of a student-athlete (Petrie \& Russell, 1995). Researchers have found that a student athlete's perception of their coaches' emphasis and encouragement of academic achievement is related to 1991). student-athlete academic performance (Lang \& Rossi,

“. . . an yana nga ak na.encounter na okay man hiya before, okay an amon ak linurong haak studies or ak coach before, super stress relationship until such time that he found out nga maida problems in my studies nag iba na an iya approach."

“. . . below the belt na it iya treatment ba ha imo."

“... Bagan naano la ako hadto kai ginpa.feel niya nga diri ako part han made me feel like I was not part of the team.)

team, sugad ba." $\{\mathrm{He}$

According to Mageau and Vallerand (2003), the coach-athlete relationship is one of the most crucial determinants of an athlete's level of motivation. Coaches are in a position to positively or negatively influence the academic achievement of their student-athletes. Unfortunately, due to the pressures associated with coaching "bigtime" college athletics, coaches tend to focus less on the student-athletes' academic prowess and more on their athletic prowess.

\section{Peer Pressure}

As stated by Kirk (2020), peer pressure refers to the capability of a peer group in encouraging an individual to change his/her behaviors, beliefs that are compatible with group norms. While most educators believe that peer pressure influences children's academic performance, Kirk (2000) observes that few studies have been done to prove this belief.

Peer pressure is defined as when people your age encourage or urge you to do something or to keep from doing something else, no matter if you want to do it or not (Ryan, 2000).

“... pagsulod ko 1st year, diri man talaga maiiwasan nga maida kita

mga frinds nga mga B.I. pero ada manla iton ha imo self kun mapadara $\quad k a$. First year 1st sem, okay pa ako hadto, tuhay pa ako hadto. But pagsulod han 2nd year 1st sem, ngada na ako hadto bagat, nadadara na talaga ako nak mga sangkay like "masulod ka?" masiring hira "diri ak masulod, Ayaw kita pagsinulod" bagan sugad,"

The subtler form of peer pressure is known as peer influence, and it involves changing one's behavior to meet the perceived expectations of others (Burns \& Darling, 2002).

“... nadadara la liwat ako, so okay ma.bebehind daw ako kun diri ako umupod ha ira, bagan sugad ba. So, nadara talaga ako hadto ha ira, so bagat ako waray naman ak mahimo."

“... . akon mga grades han 2 nd year 2 nd semester puro letters tanan, waray number ---- as a result hapit na ak matanggal dinhi (university 


\section{Sports Involvement}

"No. Not at all. It depends on you lang talaga kun tawo ha imo paligid lalo na ha imo studies."

Good role models can inspire one by demonstrating the ideal, desired self-discovery of the potential achievement that one can aim for and the root to fulfill them. A negative role model can inspire one by illustrating disasters and highlighting mistakes that must be avoided to prevent them. Since peer groups are a vital aspect of the growth process, they may have a negative influence on young people due to peer pressure, which is the pressure from others in certain activities, and peer conformity which is the pressure imposed by others in such practices, and peer enforcement.

\section{Conclusion}

The study found out that sports involvement particularly the softball program in this certain university does not negatively affect student-athlete's academic performance. Student-athletes need to choose peers who are positive role models or influence them in illustrating an ideal, desired self-highlighting possible achievement that one can strive for. Coaches are more focused on the athletic prowess of student-athletes rather than their academic prowess.

\section{Recommendation}

The following recommendations are made:

1. Students should not hesitate to participate in sports because it does not negatively affect academic performance.

2. Sports involvement among students should be encouraged to develop not only physical strength and agility but also mental alertness.

3. Choosing peers is encouraged to avoid misfortunes and unpleasant outcomes in terms of academic performance.

\section{References}

Apaak, D., \& Sarpong, E. O. (2015). Internal Challenges Affecting Academic Performance of Student-Athletes in Ghanaian Public Universities.

Journal of Education and Practice, 6, p18-23.

Broh, B. A. (2002, January). Linking Extracurricular Programming to Academic Achievement: Who Benefits and Why? Sociology of Education, vol. 75, pp. 69-95. doi:https://doi.org/10.2307/3090254

Daley, A. J., \& Ryan, J. (2000). Academic Performance and Participation in Physical Activity by Secondary School Adolescents. Sage Journals, 91(2), page(s): 531-534.

Darley, J. (1986). Psychology. United States of America: Prentice-Hall.

Douthit, S. (2009, February 09). Student-Athletes Face More Than Academic Challenges. The News-Argus.

Fuentes, H. (n.d.). Being an Athlete.

Gragg, D., \& Flowers, R. D. (2014). Factors that Positively Affect Academic Performance of African American Football Student-Athletes.

Journal for the Study of Sports and Athletes in Education, 8(2), Pages 77-98.

Hamm, M. (2005). "On Self-Esteem and Sports". Department of State 301 4th St. W. Washington, D.C. 20547 United States of America: eJournal USA: Global Issues.

Hurlock, E. (1982). Developmental Psychology. Philippines: McGraw Hill Inc.

JacAngelo, N. P. (2003). The relation of sports participation to the academic performance of high school students. ProQuest ETD Collection for FIU.

Jergovic, D. (2002). The Impact of Athletic Participation on the Academic Achievement of American Adolescents. eLibrary.ru.

Korir, D. D., \& Kipkemboi, F. (2014, March). The Impact of School Environment and Peer Influences on Students' Academic Performance in 
Vihiga County, Kenya. International Journal of Humanities and Social Science, volume 4.

Lumpkin, A., \& Favor, J. (2013). Comparing the Academic Performance of High School Athletes and Non-Athletes in Kansas 2008-2009. Journal of Applied Sport Management, volume 4(issue 1).

Padilla, A., \& Baumer, D. (1994, May 1). BIG-TIME COLLEGE SPORTS: MANAGEMENT AND ECONOMIC ISSUES. Journal of Sport and Social Issues, Volume 18(issue 2), pages 123-143. doi:https://doi.org/10.1177/019372394018002003

Rothschild-Checroune, E., Gravelle, F., Dawson, D., \& Karlis, G. (2012). Balancing academics and athletic time management: A qualitative exploration of first-year student-athletes' university football experiences. Loisir et Société / Society and Leisure, Pages 243-261.

Shosha, G. A. (2012). EMPLOYMENT OF COLAIZZI'S STRATEGY IN DESCRIPTIVE PHENOMENOLOGY: A REFLECTION OF A RESEARCHER. European Scientific Journal, ESJ, 8(27). doi:https://doi.org/10.19044/esj.2012.v8n27p\%p

Sitkowski, L. S. (2008). The Effects of Participation in Athletics on Academic Performance among High School. A Dissertation Presented to The Faculty of the School of Education Liberty University.

Watt, S. K., \& Moore, J. L. (2001). Who Are Student-Athletes? New Directions for Student Services: Student Services for Athletes, 2001(93), 7 18. doi:https://doi.org/10.1002/ss.1 